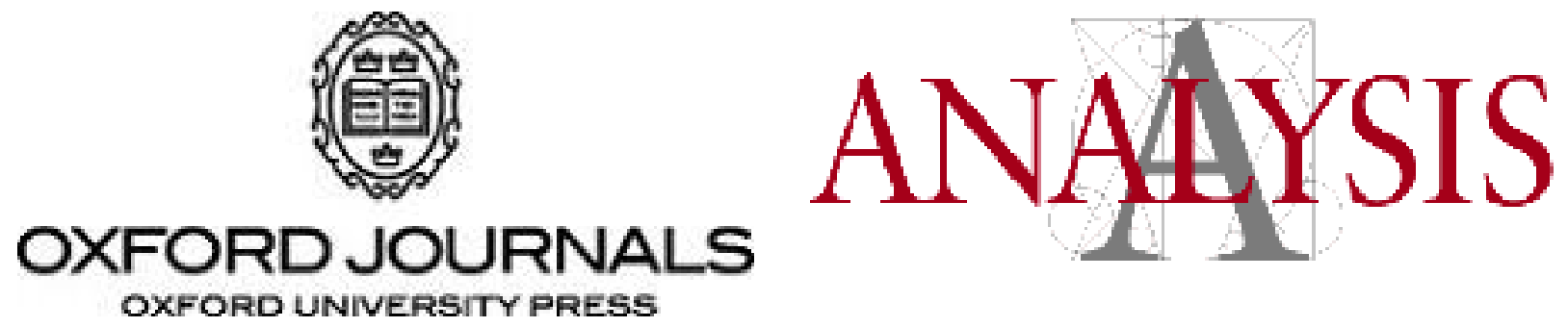

\author{
Sorabji and the Dilemma of Determinism \\ Author(s): Paul Russell \\ Source: Analysis, Vol. 44, No. 4 (Oct., 1984), pp. 166-172 \\ Published by: Oxford University Press on behalf of The Analysis Committee \\ Stable URL: http://www.jstor.org/stable/3327377 \\ Accessed: $11 / 06 / 201121: 33$
}

Your use of the JSTOR archive indicates your acceptance of JSTOR's Terms and Conditions of Use, available at http://www.jstor.org/page/info/about/policies/terms.jsp. JSTOR's Terms and Conditions of Use provides, in part, that unless you have obtained prior permission, you may not download an entire issue of a journal or multiple copies of articles, and you may use content in the JSTOR archive only for your personal, non-commercial use.

Please contact the publisher regarding any further use of this work. Publisher contact information may be obtained at http://www.jstor.org/action/showPublisher?publisherCode=oup.

Each copy of any part of a JSTOR transmission must contain the same copyright notice that appears on the screen or printed page of such transmission.

JSTOR is a not-for-profit service that helps scholars, researchers, and students discover, use, and build upon a wide range of content in a trusted digital archive. We use information technology and tools to increase productivity and facilitate new forms of scholarship. For more information about JSTOR, please contact support@jstor.org. 
a world in which events happen because there are sufficient antecedent conditions for their happening. The 'random model' is not one that we are willing to accept as a reflection of how things are. The rationale for $\left(\mathrm{P}^{\prime}\right)$ depends on such a model, and so there is no reason whatsoever to accept $\left(\mathbf{P}^{\prime}\right)$.

\title{
VI
}

We have looked rather carefully here at the claim that it is not possible that an event happens at some time after an infinite number of events have passed, because, at any point in an infinite series of events, 'it would have happened already'. We have not found any rationale for it, and it is now extremely difficult even dimly to imagine how such a thing might go. On the other hand, it is hardly less difficult to imagine how one could give a demonstration of the principled impossibility of there being any such rationale. Grand 'Kantian' manoeuvres are seldom successful. Specific arguments need specific consideration.

University of Missouri-St Louis, CDavid A. Conway 1984 8001 Natural Bridge Road,

St. Louis, Missouri 63121, U.S.A.

\section{SORABJI AND THE DILEMMA OF DETERMINISM}

\author{
By PAul Russell
}

\footnotetext{
TN Necessity, Cause and Blame (London: Duckworth, 1980) Richard Sorabji attempts to develop a notion of moral responsibility which does not get caught on either horn of a well known dilemma. One horn is the argument that if an action was caused then it must have been necessary and therefore could not be one for which the agent is responsible. The other horn is the argument that if the action was not caused then it is inexplicable and random and therefore not something which the agent can be responsible for. Sorabji denies that what is caused is always necessitated. Causes are primarily explanatory rather than necessitating. This established, Sorabji hopes to show that action open to moral scrutiny may be caused without being necessitated and the dilemma collapses. I will argue that this strategy runs into serious difficulties.
} 
Sorabji argues that desires and beliefs are causes of action, and clearly he means to suggest that they are efficient causes of action (cf. p. 40). These desires and beliefs, it is implied, have weights which may or may not be 'equally balanced' when they oppose one another (I use the term 'weight' here to correspond with Sorabji's metaphor of 'scales', cf. pp. 30-1). Sorabji offers two examples in support of his claim that human action may be caused without being necessitated. In Chapter Fourteen he considers the case of a child who has equal but opposing desires. On the one hand the child wants to take another child's toy which appeals to him but on the other hand he equally wants to please and obey his parents. As it happens the child takes the toy but in the very same circumstances the child could have acted in the other way' (p. 232n - my emphasis). We can, however, give an explanation and cite a cause of the child's action; namely, 'that set of incentives which favoured taking the toy'. Thus, while there is 'no answer available for someone who... wants to be told why the child acted on the one set [sc. of incentives] rather than the other' there is nevertheless an explanation for why the action occurred. In this way, it is argued, the problem of randomness may be overcome.

In Chapter Two Sorabji offers an example "in which the case for and against a decision does not seem equally balanced'. An agent may have 'overwhelming' reason for attending a lecture and 'nine times out of ten in such circumstances a man may act accordingly'. However, the agent also has some reason for not attending the lecture and therefore may sometimes not attend. (If 'scales' are balanced at a ratio of 9:1 they always go to the weightier side - not at a ratio of 9:1. How, given the analogy, does Sorabji account for the exceptional case? If the 'scales' do not always come down on the weightier side how do we establish the relative weight of rival sets of incentives? This sort of difficulty suggests that the metaphor of 'scales' is perhaps not a very happy one.) In other words, Sorabji suggests that under identical circumstances $C$ an agent may usually do $X$ (i.e. attend a lecture) for given reasons, say $R_{1}$, but he may occasionally do $\mathrm{Y}$ for other conflicting reasons, say $\mathrm{R}_{2}$. Hence under the said circumstances neither $\mathrm{X}$ or $\mathrm{Y}$ was necessitated, though doing $X$ was more probable because $R_{1}$ was weightier than $\mathbf{R}_{2}$. Nevertheless, whether $\mathrm{X}$ or $\mathrm{Y}$ occurs they will be explicable; $\mathrm{X}$ in terms of $\mathrm{R}_{1}$ and $\mathrm{Y}$ in terms of $\mathrm{R}_{2}$. However, a serious problem remains and one which curiously does not seem to trouble Sorabji very much.

Sorabji admits that what cannot be explained is why the agent does X (acts on $R_{1}$ ) rather than $Y$ (acting on $R_{2}$ ) or vice versa. 'But then ought we to expect', he continues, 'that there will be an explanation available corresponding to every contrast that we care 
to choose?' (p. 31). Perhaps we need not be able to answer the question which asks why an agent does one given action rather than any other action. But there is another distinct question which does seem more pressing: given that the agent has a set of actual rival desires and beliefs $\left(R_{1}, R_{2}, \ldots R_{n}\right)$ why, in any given case, does the agent act on some and not others? Let us call this the comparative question. In effect the comparative question asks if the agent can determine which set of incentives become his will. (The notion of will I use here is that of an effective set of incentives - one that moves the agent to undertake an action.) Sorabji seems to think not, and in this he certainly parts company with traditional libertarianism. What matters, it seems, is that when we do act there is some set of incentives which explain the action but do not necessitate it.

It seems clear, then, that the crucial issue is whether or not Sorabji is right in claiming that we need not be concerned about being unable to explain why an agent acts on one set of incentives rather than others which are also actually his. That is to say, can we ignore the comparative question and dismiss it as irrelevant to the issue of moral responsibility?

Let us assume that the difference between $\mathrm{X}$ and $\mathrm{Y}$ is morally significant. Action $\mathrm{X}$, let us suppose, is some morally repugnant action (e.g. pushing an old lady in front of a bus) explicable in terms of a given set of incentives, $R_{1}$ (e.g. a dislike of old people, and a belief that this lady is one such person). Action $\mathrm{Y}$, by contrast, is some morally commendable action (e.g. helping the old lady across the road) explicable in terms of another distinct set of incentives, $R_{2}$ (e.g. a love of one's fellow human beings, a pleasure in helping people and a recognition that help was required). Under conditions $\mathrm{C}$ the agent has overwhelming reason to do $\mathrm{Y}$ and, let us assume, 99 times in 100 would act on $R_{2}$. Despite this he does $\mathrm{X}$ and $\mathrm{R}_{1}$ thereby becomes his will. Sorabji's argument suggests that because $X$ was not necessary, is explicable in terms of $R_{1}$, and the agent could categorically have done $\mathrm{Y}$ he is (ceteris paribus) responsible. It does not matter, so it seems, that the agent had other much stronger and wholly different beliefs and desires which he did not act on. Nor does it matter, apparently, that he was unable to determine whether he acted on $R_{1}$ or $R_{2}$ - in other words, determine whether $\mathrm{R}_{1}$ or $\mathrm{R}_{2}$ became his will.

It may be argued that if the agent did in fact act on $R_{1}$ rather than $R_{2}$ then he must have opted for $R_{1}$ in preference to $R_{2}-$ thereby determining $\mathrm{X}$ in preference to $\mathrm{Y}$. That is to say, when we act on $R_{1}$ rather than $R_{2}$ there must have been some 'new rival temptation or force' which 'tips the scales' in favour of $\mathbf{R}_{1}$. This 
assumption of the determinist is, Sorabji claims, simply a 'declaration of faith' (pp. 30-1). We require no new rival temptation or force to distinguish cases where we do $\mathrm{X}$ from those where we do Y. In identical circumstances (i.e. $C$ ) either $R_{1}$ or $R_{2}$ could be efficacious. There is no further influence of the agent which accounts for the occurrence of one action rather than the other.

Consider the following contrast. Suppose that in given conditions $C$ we have two sets of incentives, $R_{1}$ and $R_{2}$. In one case both $R_{1}$ and $R_{2}$ are causally determined and $R_{1}$ in turn necessitates action $\mathrm{X}$. In the second case $\mathrm{R}_{1}{ }^{*}$ and $\mathrm{R}_{2}{ }^{*}$ may cause but cannot necessitate actions $\mathrm{X}^{*}$ and $\mathrm{Y}^{*}$ respectively - either alternative being quite possible. Given that $\mathrm{X}^{*}$ occurs it will have been caused but unlike the first case (i.e. $X$ ) it will not have been necessitated. Sorabji would deny that the first case is an instance of morally free or responsible action because although the action was caused by the agent it was 'necessary all along'. How, then, would he regard the second case? As an action that was caused by the agent but not necessitated he would seem to regard it as one for which the agent is responsible. There is, however, no greater scope for agency in this case than in the first. The agent cannot determine whether he acts on $R_{1}$ or $R_{2}$ and so he no more determines which set of incentives becomes his will in this case than in the first case. That is to say, the opening up of possible actions in the second case does not increase the agent's influence over what he does. In both cases the agent fails to act on $\mathrm{R}_{2}$ (or $\mathrm{R}_{2}{ }^{*}$ ). In the first case necessarily, in the second case because of chance. Accordingly, the lack of necessity in the second case does not contribute to the agent's moral freedom.

What is disturbing about Sorabji's account of the agent's conduct in these circumstances is that it suggests that what the agent does within the range presented by $C$ (i.e. $\mathrm{R}_{1}, \mathrm{R}_{2}, \ldots \mathrm{R}_{\mathrm{n}}$ ) is simply a matter of chance. The nature and character of the actions which the agent produces in these circumstances will be as random and subject to chance as the 'rate and route' of radioactive emissions (Sorabji, it should be noted, uses this analogy between radioactive emissions and human conduct; cf. pp. 28-30). While it is certainly true that such actions are produced by the agent's will, it is equally clear that the agent can no more determine which set of incentives he will act on (i.e. which course of action he will pursue) than 'the lump of radioactive material' can determine the rate and route of its emissions. Thus, clearly in these circumstances it is not up to the agent how he wills.

It may be suggested that Sorabji's position can be defended against this line of criticism if we simply assume that 'a man is responsible (excusing conditions aside) for what he does by will, regardless of the origin of his will'. However, for Sorabji's purposes this argument proves too much; it would serve equally well as a defence of the compatibilist position (a position which Sorabji explicitly rejects). That is, if we adopt this defence for Sorabji's 
position then an agent could be justifiably held responsible for an action which was necessitated, as long as it was the agent's will that brought that action about.

The above considerations establish that acting on $R_{1}$ does not of itself adequately eliminate the problem of randomness as Sorabji thinks. He has limited the range of randomness (i.e. by excluding those actions with no causal connection with $\mathrm{C}$ and by establishing a causal connection between the action in question and $\mathrm{C}$ ) but within $\mathrm{C}$ the randomness persists. In other words, within the range presented by $C\left(R_{1}, R_{2}, \ldots R_{n}\right)$ it is simply a game of roulette as to what action will follow. That $\mathrm{I}$ do $\mathrm{X}$ rather than $\mathrm{Y}$, and therefore that I am condemned rather than praised, becomes a matter of chance (whether the 'odds' are 1:100, 1:10, or 1:2 does not matter).

\section{III}

There is no denying that at first glance Sorabji's attempt to resolve the dilemma of determinism would seem to satisfy the demands of both libertarians and compatibilists. On the one hand his account gives libertarianism the categorical freedom (i.e. the possibility of doing otherwise in identical circumstances) which it seeks while, on the other hand, it meets the compatibilist demand that action be caused by the (antecedent) willings of the agent and not mere random happenings. However, despite this initial plausibility, I believe that both the traditional libertarian and the orthodox compatibilist would argue that Sorabji's theory suffers from serious defects. Their dissatisfaction, I suggest, is indicative of the fact that, for different reasons, neither party would accept that the comparative question is irrelevant to the difficulties which the dilemma of determinism presents us with.

From the traditional libertarian point of view Sorabji's thesis suffers from the same fatal flaw as the compatibilist's position. Namely, on Sorabji's account the agent cannot determine which of the pre-established alternative sets of incentives he acts on. While libertarians, notoriously, find it difficult to give much coherent content to the notion of a non-phenomenal 'self', or the notion of how the will is 'determined' by this 'self', it is nevertheless quite clear why they believe that we need to appeal to these (obscure) notions. Moral responsibility, they argue, requires moral autonomy; and moral autonomy requires self-determination.

The traditional libertarian cannot accept that the comparative question is irrelevant to the issue of moral responsibility because it is clearly relevant to the issue of moral autonomy. For the traditional libertarian an agent is responsible in so far as he (i.e. a non-phenomenal 'self') determines his antecedently undetermined will. Thus the explanation for why an agent in circumstances $C$ does $\mathrm{X}$ rather than $\mathrm{Y}$ is that he (i.e. the 'self') chose to act on that set 
of incentives. To be able to answer the comparative question is to establish that such an agent had moral autonomy and was capable of self-determination. Hence, to dismiss the comparative question as irrelevant to the issue of moral responsibility is to dismiss the issue of moral autonomy and self-determination as irrelevant to the issue of moral responsibility.

From the orthodox compatibilist perspective Sorabji's thesis suffers from a serious defect common to all libertarian theories: it allows too much scope for the play of chance. Given Sorabji's account of the explanation of human action agents may frequently and inexplicably act contrary to their dominant inclination. This claim raises a number of difficulties from a compatibilist point of view. In particular, in these circumstances how could we accurately infer anyone's character or disposition on the basis of his actions? If agents frequently and inexplicably act out of character and contrary to their stronger inclinations we would find ourselves unable to anticipate their future actions reliably. In general, it may be argued that human motivation is more consistent and more coherent than Sorabji's model suggests. Indeed, it may be psychologically impossible to survive in a world in which people are randomly acting on rival sets of incentives. (Imagine how difficult it would be to live in a world in which everyone acts as if they had multiple personalities.) In this way, it seems clear that Sorabji's thesis suffers from the same sort of difficulties which compatibilists have found in other, traditional, libertarian theories.

For the compatibilist the only way in which the unacceptable play of chance can be eliminated is if the strongest set of incentives is the effective set of incentives and vice versa. As long as this is the case we can answer the comparative question. That is, the explanation for why an agent in circumstances $\mathrm{C}$ does $\mathrm{X}$ rather than $\mathrm{Y}$ is that the effective set of incentives (i.e. $\mathrm{R}_{1}$ ) was stronger than the alternative set of incentives available to him (i.e. $R_{2}$ ).

In short, it is not evident that Sorabji's thesis succeeds in avoiding all the major difficulties associated with the dilemma of determinism. Indeed it may be argued that in some important respects his theory gets impaled on both horns of the dilemma at once. At the heart of these difficulties lies the issue of whether or not the comparative question can be dismissed as irrelevant to the issue of moral responsibility. Sorabji assumes that it is irrelevant. However, as we have noted, to assume this is simply to beg some of the key issues that are in dispute. At the very least, therefore, we require independent arguments in support of this assumption.

In my view the dilemma of determinism is not likely to be resolved by Sorabji's suggestion that what is caused need not be necessitated. However, the fact that Sorabji's rather ingenious attempt to resolve this dilemma runs aground on the same rocks as its predecessors is itself of considerable interest. The regular failure of this sort of project suggests that philosophers approach the issue 
of moral responsibility with the wrong set of questions in mind. If we want to avoid running aground on these rocks we must chart a new course - we must ask different questions. Most philosophers, Sorabji included, approach the issue of moral responsibility by way of trying to provide some adequate account of how a responsible agent 'could have acted otherwise'. Their problem then becomes: how are those actions for which we are justifiably held responsible caused? The intractable nature of the dilemma of determinism suggests that there is something fundamentally wrong with this entire approach. ${ }^{1}$

Sidney Sussex College, Cambridge

C PAUL RusSell 1984

${ }^{1}$ I am grateful to G. A. Cohen, B. A. O Williams, S. Makin, the Editor, and especially to Richard Sorabji for helpful comments on this paper.

\section{A DYNAMIC MODEL OF TEMPORAL BECOMING}

\section{By STORRS MCCALL}

PROFESSOR J. J. C. Smart has kindly commented on a theory of time contained in a paper of mine. ${ }^{1}$ The issue is whether there is such a thing as the flow or passage of time, or whether time flow is a subjective illusion. Does time 'of itself, and from its own nature', in Newton's words, flow 'equably, without relation to anything external'? Or is the correct view of the universe that of a fourdimensional continuum, spread out in three dimensions of space and one of time, in which every event from the deepest past to the most distant future finds its place?

In such a world nothing 'flows'; were there no conscious observers there would not even be the illusion of time flow. The question of whether such flow is indeed a subjective illusion, or whether there is a real analogue to time flow, is the question Smart and I are interested in.

To be clear about what is at stake, consider the four-dimensional Minkowskian picture of the universe. The thesis that time is anisotropic is the thesis that there are physical processes which are directionally biassed, i.e. which occur always or for the most part in one temporal direction rather than in the other. For example, if you light a match outdoors on a clear, starry night a spherical shell or wave-front of photons begins to expand outwards in space.

${ }^{1}$ Storrs McCall, 'Objective time flow', Philosophy of Science 43 (1976), pp. 337-62; J. J. C. Smart, 'Time and becoming', in Time and Cause, ed. Peter van Inwagen, Dordrecht 1980, pp. 3-15. 